dendron bewohnenden Form gelang es mir trotz sorgfältigem Suchen nur 1 Stück daselbst zu erlangen.

Craterellus cornucopioides (L.). In Eichenwaldungen bei Reichenhaag nächst Pyhra.

Guepinia helvelloides (DC.). Zerstrent an Waldrändern bei Hohenberg, einzeln in der Krummholzregion des Göllers.

Phallus impudicus L. Vom Director F. Hübner an mehreren Stellen der Umgebung von Kreeisbach bei Wilhelmsburg aufgefunden.

Geaster fornicatus (Huds.). Das einzige von dieser Art bei Pyhra aufgefundene Exemplar zeigte folgende seltsame Bildung. Während die innere Peridie sich in der bekannten Form entwickelt hatte (bleigrau, zartwandig), war gewissermassen eine doppelte äussere Peridie vorhanden, indem die bekanntlich fast stets in vier Lappen sich spaltende äussere Peridie etwas über der Abgangsstelle dieser vier Lappen eine Art weiten Kragens, der ringfö̀mig die fast kugelige, innere Peridie umgab, trug. Der kragenförmige Körper erreichte ungefähr die Hälfte der Höhe der inneren Peridie und stellte ein weites Becken dar, ans welchem eben letztere herausragte; in Farbe, Consistenz und mikroskopischer Structur stimmte er ganz mit der äusseren Peridie überein, indem or ebenfalls aus grosszelligem, dünnwandigem PseudoParenchym bestand. Der scharf abgeschnittene freie Rand dieses Gebildes war Anfangs fast ganz, nur hin und wieder leicht eingerissen; bei dem unvermeidlichen Anfassen zum Zwecke der Untersuchung bildeten sich aber in der sehr gebrechlichen Substanz tiefere Einrisse, die schliesslich zum Zerspalten des Ringes in mehrere unregelmässige Lappen, die sich auch mit grösster Leichtigkeit am Grunde ablösten, führten. Bei der sonstigen Uebereinstimmung mit Geaster fornicatus (Hudson) kann es sich hierbei wohl nur um eine seltene Bildungsabweichung handeln.

Choiromgces maeandriformis Vittadini. Mehrere von faustgross bis nussgross in ihren Dimensionen wechselnde Exemplare in dichten, humosen Wäldern bei Kreisbach nächst Wilhelmsburg.

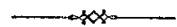 \\ Potentilla Andraejowskii n. sp.
}

Von Br. Blocki.

Diagnose: Wurzelstock eine centrale Blattrosette treibend, um welche ringsherum die Stengel niederliegen. Stengel aus liegender Basis schwach aufsteigend, bis $3 \mathrm{Dm}$. lang, fast von der Mitte an locker doldenrispig, filzig und aufrechtabstehend behaart. Wurzelblätter, sowie untere Stengelblätter fünfzählig, langgestielt, obere Stengelblätter kurzgestielt und dreizählig. Dì Blätter der Blattrosetten zweigestaltig: die Theilblättchen der unter- 
sten Rosettenblätter v erkehrteiförmig, beiderseits mit drei kurzen, eiförmigen, stumpfen Zähnen besetzt, jene der übrigen Rosettenblätter grösser, vorkehrtlänglichlanzettlich (nicht keilförmig), tief eingeschnittengosägt, beiderseits mit vier bis sechs länglichen, stumpflichen, aufrecht abstehenden Zähnen versehen, das mittlere (bei den meisten Rosettenblättern) zwei- bis dreispaltig, bis $2.5 \mathrm{Cm}$. lang. Untere Stengelblätter von der Gestalt der Rosettenblätter; die Theilblättchen der oberen Stengelblätter lineallänglich, vorn beiderseits mit drei bis vier linealen, st a mpflichen, sehr tief eingeschnittenen, abstehenden Zähnen. Alle Blätter am Rande schwach umgerollt, oberseits dicht anliegend behart, graugrünlich, unterseits dicht graufilzig (nicht weissfilzig) und an den Nerven langhaarig, deutlich nervig. Untere Nebenblätter lanzettpfriemlich, obere schief eilanzettlich. Blumenblätter klein. Kelch aussen dicht anliegend behaart; äussere Kelchlätter lineallänglich, innere eiförmig, etwas länger als die äusseren. Fruchtköpfchen ziemlich gross, bis $5 \mathrm{Mm}$. breit. Blüthenstiele ziemlich dick (nicht fadenförmig, wie bei $P$. Wiemanniana Günth. et Schum. und $P$. rhenana M. P. Müller), nach dem Verblühen der Blüthen zurückgebogen.

Standort: An grasigen Sandtriften auf der "Kortumowa góra" bei Lemberg (Galizien), zablreich - nicht weit vom Standorte der Potentilla Knappii m. und P. thyrsiftora Zimm. Auch kommt sie - wiewohl viel seltener - auf Sandtriften in Hołosko und Brzuchowice (bei Lemberg) ror.

Lemberg, im November 1888.

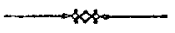

\title{
Bemerkungen zur Flora von Ungarn.
}

\author{
Von Dr. L. Simonkai.
}

VIII.

Achillea tanacetifolia All. flora pedem. I (1785), pag. 183 and 166, und ihr Formenkreis.

Es hat sowohl den jetzigen, als den früheren älteren Botanikern schon so manches Kopfbrechen verursacht, um es zu deuten, was eigentlich unter Achillea tanacetifolia All. zu verstehen ist, und wie sich diese Species Allioni's zu der Achillea magna L. spec. ed II, pag. 1267 (1763), dann zul der $A$. compacta Lamarck dict. I (1783), pag. 27, der $A$. distans W. et K. in Willd. spec. III (1800), pag. 2207, der A. stricta Schleicher in Koch synops. (ed 1837), pag. 374, und der $A$. pseudotanacetifolia Wierzb. in Reichb. icones XVI (1854), pag. 69, tab. 136, Fig. 1027 verhält. In südlicherem und östlichem Ungarn kommen überall stattliche Achilleen vor, 